\title{
Long-term impact of bronchopulmonary dysplasia on pulmonary function
}

\author{
Jennifer S Landry MD ${ }^{1}$, Tiffany Chan², Larry Lands MD PhD², Dick Menzies MD ${ }^{1}$
}

\begin{abstract}
JS Landry, T Chan, L Lands, D Menzies. Long-term impact of bronchopulmonary dysplasia on pulmonary function. Can Respir J 2011;18(5):265-270.
\end{abstract}

BACKGROUND: Bronchopulmonary dysplasia (BPD) and the longterm respiratory consequences of prematurity are unfamiliar to adult respirologists and remain under-recognized entities to adult caregivers. In Canada, the incidence of preterm births and its main chronic respiratory complication, BPD, have increased over the past 25 years.

OBJECTIVE: To describe the posthospitalization morbidity, medication use, health care use and pulmonary function tests of a large cohort of individuals with preterm birth complicated by BPD.

METHODS: A retrospective review of the hospital records of 322 preterm infants with BPD was conducted. Outcome variables were compared across levels of disease severity. Differences between groups were tested with oneway ANOVA for continuous variables and the Mantel-Haenszel $\chi^{2}$ test for ordinal variables.

RESULTS: Outcomes after the initial hospitalization that were associated with the initial severity of BPD were as follows: hospital readmissions in the first two years of life, the presence of developmental delay, forced expiratory volume in $1 \mathrm{~s}$ and forced vital capacity on pulmonary function tests in patients between eight and 15 years of age.

CONCLUSION: Initial BPD severity was an important predictor of pulmonary function abnormality and health care use during childhood.

Key Words: Bronchopulmonary dysplasia; Prematurity; Pulmonary function

$\mathrm{B}$ ronchopulmonary dysplasia (BPD) and the long-term respiratory consequences of prematurity are unfamiliar to adult respirologists and remain under-recognized entities to adult care givers. Well described in the pediatric population, these young adults who were born prematurely and experienced respiratory complications are joining the rank of a growing population of Canadians with chronic obstructive lung disease, and are developing this disease at an even earlier age than their contemporaries.

Preterm birth has been an under-recognized global health issue, partly because of a lack of data regarding the extent of the problem. In 2005, 13 million preterm babies were born worldwide. North America (106/1000 births) has the second highest rate of preterm birth after the African countries (1). Preterm births also seem to be increasing in number. In Canada and the United States, the rate of preterm birth has increased by $35 \%$ in the past 25 years, mainly because of assisted reproduction and older maternal age at first delivery (1). In Canada, the rate of preterm birth, defined as a gestational age of younger than 37 weeks, was $6.6 \%$ in 1991, 7.1\% in 1996 and reached $7.6 \%$ in 2006, and accounts for $75 \%$ to $85 \%$ of all perinatal mortality $(2,3)$. According to the 2009 White Paper Report of the March for Dimes Foundation (1), more than one million infants die every year due to prematurity, while those who survive are at an increased risk of morbidities such as cerebral palsy, bronchopulmonary dysplasia, blindness and hearing loss (1). After the initial description of BPD in 1967 by Northway et al (4), many advances have been made in our understanding of the pathophysiology of this disease. With advances in neonatal care over the past three decades, a

\author{
Les répercussions à long terme de la dysplasie \\ bronchopulmonaire sur la fonction pulmonaire
}

HISTORIQUE : Les pneumologues pour adultes connaissent mal la dysplasie bronchopulmonaire (DBP) et les conséquences respiratoires à long terme de la prématurité, et pour les dispensateurs de soins pour adultes, ces pathologies demeurent des entités méconnues. Au Canada, l'incidence d'accouchements prématurés et leur principale complication respiratoire chronique, la DBP, ont augmenté depuis 25 ans.

OBJECTIF : Décrire la morbidité après l'hospitalisation, l'utilisation de médicaments et les explorations fonctionnelles respiratoires d'une vaste cohorte d'individus prématurés atteints de DBP complexe.

MÉTHODOLOGIE : Les chercheurs ont mené une analyse rétrospective des dossiers médicaux de 322 nourrissons prématurés atteints de DBP. Ils ont comparé les variables d'issue selon les degrés de gravité de la maladie. Ils ont vérifié les différences entre les groupes au moyen de l'ANOVA unidirectionnelle pour ce qui est des variables continues, et du test $\chi^{2}$ de Mantel-Haenszel pour ce qui est des variables ordinales.

RÉSULTATS : Les issues après l'hospitalisation initiale qui s'associaient à la gravité initiale de la DBP s'établissaient comme suit : les réhospitalisations pendant les deux premières années de vie, la présence d'un retard du développement, le volume expiratoire maximal par seconde et la capacité vitale forcée aux explorations fonctionnelles respiratoires chez les patients de huit à 15 ans.

CONCLUSION : La gravité initiale de la DBP était un prédicteur important d'anomalie de la fonction pulmonaire et de soins de santé pendant l'enfance.

greater proportion of preterm infants are surviving the initial complications of prematurity, and are now reaching adulthood in ever increasing numbers. Furthermore, the improved survival of very preterm infants has led to an increasing incidence of pulmonary complications among these infants (5), and increased numbers of adolescents and young adults with sequelae of BPD (6). This has clinical implications because their course, prognosis and treatment are largely unknown. This also has health system implications because of increased resource use. In 2000, the National Institute of Child Health and Human Development sponsored a workshop to arrive at a consensus definition for BPD (7). The final definition was that an infant requiring at least 28 days of supplemental oxygen should be considered to have BPD, and that infants should be reassessed at 36 weeks' postmenstrual age (or 52 days of life if born after 32 weeks) to establish disease severity.

In the past 10 years, several studies have described the long-term sequelae of survivors of preterm births as these subjects reach adolescence and young adulthood (8-18). Most of these studies focused on pulmonary and neurological outcomes - the two systems most affected by prematurity and low birth weight $(19,20)$. One study reported $10 \%$ lower forced expiratory volume in $1 \mathrm{~s}\left(\mathrm{FEV}_{1}\right)$ (\% predicted) in 12 survivors of moderate to severe BPD (mean age 17.7 years) when compared with preterm infants with either mild or no BPD (18). The present study was conducted to provide a detailed description of the long-term clinical characteristics of a cohort with preterm birth who developed BPD of varying degrees of severity as defined using the National Institutes of Health (NIH) consensus criteria.

${ }^{1}$ Respiratory Epidemiology $\mathcal{E}$ Clinical Research Unit, McGill University; ${ }^{2}$ Montreal Children's Hospital, McGill University Health Centre, Montreal, Quebec

Correspondence and reprints: Dr Jennifer S Landry, Montreal Chest Institute-McGill University Health Centre, 3650 Avenue Saint-Urbain, Room K1.18, Montreal, Quebec H2X 2P4. Telephone 514-934-1934 ext 32152, fax 514-843-2083, e-mail jennifer.landry@mcgill.ca 


\section{METHODS}

Subjects and setting

The inclusion criteria for the study were a diagnosis of BPD (defined by the NIH consensus [5]) in subjects born before 37 weeks' gestational age and admitted between January 1, 1980, and December 31, 1992, to the Montreal Children's Hospital (MCH) (Montreal, Quebec). The $\mathrm{MCH}$ is a tertiary pediatric hospital with specialized neonatal care that serves as a referral centre for the province of Quebec. The study was approved by the Research Ethics Board of the McGill University Health Centre (Montreal, Quebec).

\section{Data collection}

Data were abstracted from hospital records using a standardized data collection sheet. Information collected included demographic data, maternal, prenatal and perinatal history, delivery, neonatal hospital course and main neonatal outcomes. Secondary diagnoses, such as the presence of necrotizing enterocolitis, a diagnosis of neonatal pneumonia or sepsis within the first 28 days of life, the occurrence of a pneumothorax within the first $48 \mathrm{~h}$ of life, retinopathy of prematurity or intraventricular hemorrhage, were identified from the discharge summary and were confirmed by a detailed chart review. Data regarding the use of mechanical ventilation or noninvasive ventilation, such as nasal continuous positive airway pressure (CPAP) and supplemental oxygen, were recorded. For patients followed at the $\mathrm{MCH}$ after the first hospitalization, the number and mean length of stay of readmissions were recorded. Use of inhaled short-acting betaagonists and inhaled corticosteroids were recorded. The most recent routine chest $\mathrm{x}$-ray report was also reviewed, specifically excluding chest $\mathrm{x}$-ray examinations performed during an acute infectious presentation or at the time of hospitalization for an acute respiratory illness. Results of pulmonary function tests were recorded when available. Long-term complications, listed below, were also abstracted from written reports from various specialists. If a subject was transferred back to the initial referring institution, this was recorded and the date of transfer was noted.

\section{Definitions}

Preterm birth: Gestational age of younger than 37 weeks (259 days). BPD: The need for supplemental oxygen for at least 28 days (21). Disease severity was graded based on an assessment performed at 36 weeks' postmenstrual age (or 56 days of life if born after 32 weeks). Mild disease was defined as breathing room air at that time (fraction of inspired oxygen $\left[\mathrm{FiO}_{2}\right]$ of 0.21 ), moderate disease as requiring an $\mathrm{FiO}_{2}<0.30$, and severe disease as needing an $\mathrm{FiO}_{2} \geq 0.30$, or requiring positive pressure ventilation. Infants with $\mathrm{BPD}$, who died of respiratory causes before the assessment date, were considered to have severe disease. These definitions were based on the NIH consensus definition of BPD established in 2000 (22).

Radiological studies compatible with BPD: A chest $\mathrm{x}$-ray report that included the phrase "compatible with BPD or chronic lung disease" signed by a pediatric radiologist.

Developmental delay: A report from a health specialist, including but not limited to an occupational therapist, neurologist or pediatrician specialized in the follow-up of preterm infants, concluding that development delay, based on corrected gestational age, was present.

Attention-deficit and hyperactivity disorder: A report from a pediatric psychiatrist confirming the presence of an attention-deficit hyperactivity disorder, based on criteria from the DSM-IIIR or DSM-IV.

Neurological impairment: A report from a neurologist or a neurosurgeon confirming the presence of a neurological impairment.

Hearing impairment: Based on a formal audiology testing report confirming a hearing deficit.

Low vision: Based on findings generated by consultation with an ophthalmologist.

Structural airway abnormalities: Defined by a report from an otorhinolaryngologist, bronchoscopy report or the need for surgical intervention on the upper airways or trachea.

\section{Statistical analyses}

Incidence of complications: For developmental delay, neurological impairment, and hearing and visual impairment, the estimates presented represent the cumulative incidence of each condition up to two years of age among subjects who were actively followed at the $\mathrm{MCH}$ to that age $(\mathrm{n}=163)$. The subjects lost to follow-up were not included in the analysis (even if the condition occurred before they were lost). The cumulative incidence of wheezing episodes, 'asthma', structural airway problems and cor pulmonale included all children diagnosed with these conditions up to five years of age, in subjects still actively followed to that age $(n=103)$. For attention-deficit hyperactivity disorder, because this diagnosis is often made later in the course of a child's life, it was assessed at any point during follow-up and the incidence was based on the total study population that was seen at least once following the initial discharge. The point prevalence of chest $\mathrm{x}$-ray abnormalities and medication use was estimated at several ages, using all those followed up to that age as the denominator.

Infants were grouped into three categories of disease severity: mild, moderate and severe as defined above. Baseline and follow-up characteristics were compared between severity categories and/or age groups, and differences between these groups were tested for statistical significance using one-way ANOVA for continuous variables, and the Mantel-Haenszel $\chi^{2}$ test for ordinal variables. Variables identified as significant in the univariate analyses were then included in multivariate logistic regression analyses, along with the gestational age to correct for the degree of prematurity. Factors were studied for collinearity by assessing their degree of correlation and were removed if identified. The statistical significance for trend across levels of disease severity was assessed using regression analysis. $\mathrm{P} \leq 0.05$ was considered to be statistically significant. Statistical analyses were conducted using SAS version 9.1 (SAS Institute Inc, USA).

\section{Population characteristics}

\section{RESULTS}

A total of 322 preterm infants with BPD identified during their hospital course were admitted to the $\mathrm{MCH}$ over the 12-year study period. Of these, $269(83.5 \%)$ were discharged or transferred alive after a mean length of stay of 137 days. Of these subjects, $78.1 \%$ were followed-up subsequently at the $\mathrm{MCH}$ at least once, as shown in Figure 1. Of the 322 infants, 60 had mild, 123 had moderate and 107 had severe disease. Disease severity was not assessed in 32 subjects (9.9\%), primarily because they were transferred to other medical institutions before the severity assessment date but after having met the criterion for diagnosis of BPD (ie, 28 days of oxygen treatment). As shown in Figure 1, 53 infants died in hospital, 59 were transferred to another hospital, or discharged with no further follow-up, and 210 patients were discharged and had some follow-up at the MCH. Of all infants discharged alive, $62(26 \%)$ were discharged on oxygen. The mean gestational age at discharge was $334.4 \pm 117.7$ days. Antenatal, and neonatal clinical characteristics associated with BPD severity were reported elsewhere (23). Briefly, among the 322 subjects identified with BPD, the severity of this disease was associated with the following: 1 min Apgar score, gestational age, presence of very low birth weight and the occurrence of neonatal pneumonia/sepsis. The duration of invasive mechanical ventilation and the total duration of oxygen therapy were significantly greater in more severe BPD cases, as shown in Table 1.

\section{Clinical course after initial discharge}

A total of 210 subjects were followed at the $\mathrm{MCH}$ after their initial discharge. This represents $78 \%$ of subjects who were discharged alive, and $88 \%$ of subjects who were discharged directly home from the $\mathrm{MCH}$. Among the subjects followed regularly at the $\mathrm{MCH}$ after their initial discharge, the proportion with different degrees of disease severity remained relatively stable up to 12 years of age. After this age, follow-up was discontinued for more of the mild cases than for the moderate and severe cases (Figure 1). 
Of the 210 subjects seen after initial discharge, $37 \%$ had more than one outpatient visit per year, while $63 \%$ had annual visits or fewer. Of the same 210 subjects, 187 (90\%) were readmitted an average of 4.7 times, with a mean length of stay for each admission of 11.2 days. On average, three admissions occurred during the first two years of life. Details of hospital readmission according to disease severity are shown in Table 2. Hospital readmission was associated with BPD severity and, after adjustment for severity, with duration of mechanical ventilation $(\mathrm{P}<0.0001)$ and oxygen therapy $(\mathrm{P}=0.0001)$.

Medication profiles and persistence of radiological abnormalities As shown in Table 2, the use of inhaled medications was not associated with the initial severity of BPD but was associated with the total duration of supplemental oxygen $(\mathrm{P}=0.01)$, and the presence of neonatal pneumonia or sepsis $(\mathrm{P}=0.04)$ during that first admission. There was no significant relationship found between disease severity and the presence of radiological abnormalities on the most recent routine radiological follow-up (Table 2). The category 'others' was mainly composed of findings of pneumonia or nondiagnostic findings compatible with BPD such as interstitial thickening, focal or general hyperexpansion, and atelectasis (14).

Oxygen therapy, pulmonary function tests and long-term complications of prematurity

$\mathrm{FEV}_{1}$, forced vital capacity (FVC) and their ratio were significantly associated with the initial BPD severity (Table 3). Of all lung function indexes, only $\mathrm{FEV}_{1}$ was associated with another parameter - the total duration of oxygen therapy $(\mathrm{P}=0.02)$. No other parameters of lung function were associated with mechanical ventilation parameters (maximum pressure, positive end-expiratory pressure, use of traditional mechanical ventilation) versus nasal CPAP or level of $\mathrm{FiO}_{2}$ used.

Table 4 lists the incidence of known complications following preterm birth observed in the present cohort. Subjects whose BPD severity could not be classified are included in the overall category. This accounts for the difference between the number of subjects in the overall category and the number in the mild, moderate and severe categories. Table 5 shows the results of the multivariate analyses for the long-term outcomes of developmental delay, attention-deficit hyperactivity disorder and neurological impairment.

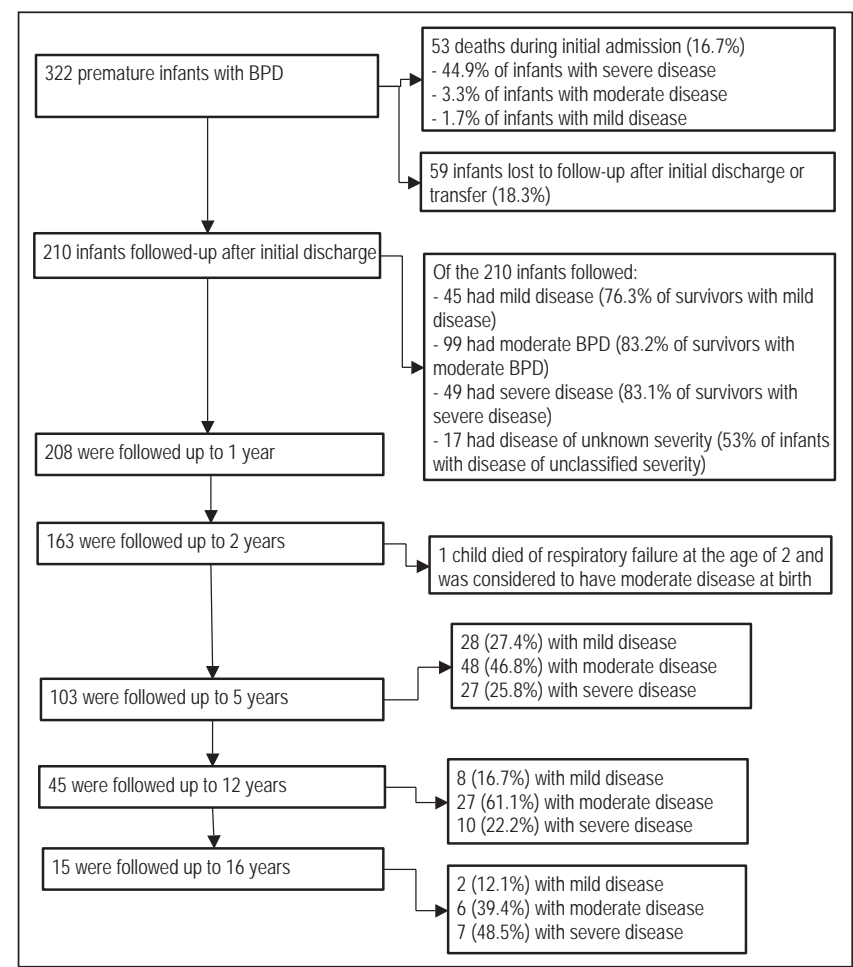

Figure 1) Number of subjects followed up according to disease severity. BPD Bronchopulmonary dysplasia

\section{DISCUSSION}

The present retrospective study described the posthospitalization course of a cohort of preterm infants who experienced the complication of BPD. Its major findings were the association of initial BPD severity with several morbidities such as hospital readmissions in the first two years of life, the presence of developmental delay and lung function abnormalities later in childhood. These findings have implications for the care of preterm infants and for the planning of health care services.

\section{TABLE 1}

Clinical characteristics associated with the initial hospitalization according to bronchopulmonary dysplasia (BPD) severity

\begin{tabular}{|c|c|c|c|c|c|}
\hline & \multirow[b]{2}{*}{ All BPD } & \multicolumn{3}{|c|}{ BPD severity } & \multirow[b]{2}{*}{$\mathbf{P}^{*}$} \\
\hline & & Mild & Moderate & Severe & \\
\hline \multicolumn{6}{|l|}{ Neonatal factors } \\
\hline $\mathrm{n}(\%$ of total) & 322 (NA) & $60(20.7)$ & $123(42.4)$ & $107(36.9)$ & - \\
\hline Gestational age, days & $195.7 \pm 21.1$ & $196.9 \pm 22.3$ & $195.6 \pm 19.9$ & $196.9 \pm 21.6$ & 0.46 \\
\hline Male sex, n (\%) & $190(59.0)$ & $32(53.3)$ & $66(53.6)$ & $70(65.4)$ & 0.04 \\
\hline Median length of hospital stay, days & 108 & 78 & 117 & 145 & $<0.0001$ \\
\hline \multicolumn{6}{|c|}{ Traditional mechanical ventilation during initial admission } \\
\hline Mechanical ventilation, n (\%) & 301 (96.5) & $56(93.3)$ & $112(94.2)$ & $107(100)$ & 0.008 \\
\hline Maximal $\mathrm{FiO}_{2}$ & $0.84 \pm 2.3$ & $0.80 \pm 0.23$ & $0.83 \pm 0.25$ & $0.88 \pm 0.22$ & 0.06 \\
\hline Median duration, days & 42 & 27 & 29 & 72 & $<0.0001$ \\
\hline \multicolumn{6}{|c|}{ Noninvasive positive pressure ventilation during initial admission } \\
\hline Median duration ${ }^{\dagger}$, days & 56 & 18 & 75 & 96 & $<0.0001$ \\
\hline Discharged home on oxygen, $\mathrm{n}(\%)$ & $62(26.1)$ & $1(1.7)$ & $33(27.7)$ & $25(42.4)$ & $<0.0001$ \\
\hline
\end{tabular}

Data presented as mean $\pm S D$ unless otherwise indicated. ${ }^{*} P$ value for trend; ${ }^{\dagger}$ The duration of supplemental oxygen consists of the entire duration of therapy, both in and out of the hospital. FiO 2 Fraction of inspired oxygen; NA Not applicable 
TABLE 2

Clinical characteristics and course following initial discharge according to bronchopulmonary dysplasia (BPD) severity

\begin{tabular}{|c|c|c|c|c|c|}
\hline & \multirow[b]{2}{*}{ All BPD } & \multicolumn{3}{|c|}{ BPD severity } & \multirow[b]{2}{*}{$\mathbf{P}^{*}$} \\
\hline & & Mild & Moderate & Severe & \\
\hline \multicolumn{6}{|l|}{ Hospital readmissions (after initial hospitalization at birth) } \\
\hline $\mathrm{n}$ & 210 & 45 & 99 & 49 & - \\
\hline Admissions & $4.7 \pm 6.1$ & $3.1 \pm 3.2$ & $4.3 \pm 3.7$ & $7.7 \pm 10.8$ & 0.002 \\
\hline Admissions younger than 2 years of age & $3.0 \pm 2.3$ & $2.3 \pm 2.3$ & $2.6 \pm 2.1$ & $3.6 \pm 2.8$ & 0.03 \\
\hline Length of hospital stay, days & $11.2 \pm 29.3$ & $18.8 \pm 59.4$ & $8.0 \pm 9.0$ & $10.9 \pm 15.1$ & $<0.0001$ \\
\hline \multicolumn{6}{|l|}{ Medication profile at most recent routine follow-up } \\
\hline $\mathrm{n}$ & 109 & 19 & 57 & 26 & - \\
\hline Age, years & $6.2 \pm 5.2$ & $4.9 \pm 4.8$ & $5.8 \pm 4.9$ & $7.8 \pm 5.6)$ & - \\
\hline Inhaled short-acting beta-agonist, number of subjects/person-year & 0.10 & 0.12 & 0.09 & 0.09 & 0.31 \\
\hline Inhaled corticosteroids, number of subjects/person-year & 0.03 & 0.03 & 0.03 & 0.04 & 0.46 \\
\hline \multicolumn{6}{|l|}{ Chest $\mathrm{x}$-ray findings at most recent routine radiological follow-up } \\
\hline $\mathrm{n}$ & 57 & 13 & 25 & 16 & - \\
\hline Age, years & $8.6 \pm 11.7$ & $5.1 \pm 5.6$ & $7.9 \pm 5.9$ & $8.4 \pm 6.8$ & - \\
\hline Normal, n (\%) & $9(15.8)$ & $2(15.4)$ & $5(20.0)$ & $2(12.5)$ & 0.09 \\
\hline Compatible with BPD/chronic lung disease, n (\%) & $39(68.4)$ & $11(84.6)$ & $16(64.0)$ & $10(62.5)$ & 0.07 \\
\hline Others, n (\%) & $9(15.8)$ & $0(0)$ & $4(16.0)$ & $4(25.0)$ & 0.06 \\
\hline
\end{tabular}

Data presented as mean $\pm S D$ unless otherwise indicated. ${ }^{*} P$ value for trend

TABLE 3

Lung function measurements according to bronchopulmonary dysplasia (BPD) severity

\begin{tabular}{lcccc}
\hline & \multicolumn{3}{c}{ BPD severity } & \\
\cline { 2 - 4 } & Mild & Moderate & Severe & $\mathbf{P}^{*}$ \\
\hline $\mathrm{n}$ & 6 & 10 & 9 & - \\
Age, years, mean $\pm \mathrm{SD}$ & $14.0 \pm 2.8$ & $13.8 \pm 1.9$ & $13.7 \pm 1.8$ & 0.62 \\
$\mathrm{FEV}_{1}$ & $93.5 \pm 9.7$ & $53.0 \pm 19.0$ & $52.2 \pm 12.5$ & 0.006 \\
$\mathrm{FVC}$ & $103.0 \pm 2.5$ & $72.0 \pm 15.8$ & $64.5 \pm 12.1$ & 0.19 \\
FEV $_{1}$ /FVC & $83.8 \pm 12.8$ & $68.8 \pm 23.7$ & $76.3 \pm 19.0$ & 0.06 \\
FEF $_{25-75}$ & $83.3 \pm 17.0$ & $43.2 \pm 33.6$ & $34.2 \pm 18.5$ & 0.001 \\
TLC & $105.7 \pm 23.8$ & $113.3 \pm 35.3$ & $110.5 \pm 9.2$ & 0.37 \\
FRC & $104.0 \pm 71.2$ & $148.0 \pm 76.9$ & $163.0 \pm 24.0$ & 0.07 \\
RV & $121.3 \pm 96.8$ & $248.5 \pm 73.6$ & $294.0 \pm 59.4$ & 0.29 \\
DLCO & - & $78.0 \pm 5.0$ & $55.5 \pm 6.4$ & -
\end{tabular}

Data presented as \% predicted \pm SD unless otherwise indicated. *Comparison between values across severity categories. DLCO Diffusing capacity for carbon monoxide; FEF $25-75$ Forced expiratory flow over the middle one-half

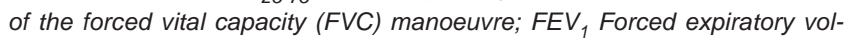
ume in $1 \mathrm{~s}$; FRC Functional residual capacity; RV Residual volume; TLC Total lung capacity

\section{Implications}

In our cohort, $83 \%$ of infants who were discharged alive and followed at the $\mathrm{MCH}$ had at least one admission in the first two years of their life. This is substantially higher than the 50\% readmission rate reported previously (24). This may, in part, have reflected the fact that milder cases were less likely to be followed at the $\mathrm{MCH}$ after their discharge. Oxygen therapy was discontinued after a mean duration of 20 weeks, but severe cases were maintained on oxygen for an average of 40 weeks which, when considering their corrected gestational age at discharge, meant that subjects with severe BPD were weaned off oxygen after an average of 14 months. More than one-half of the children (54\%) received an inhaled short-acting beta-agonist in their first few years of life - presumed to represent the occurrence of wheezing episodes. Inhaled corticosteroids were used in $20.4 \%$ of subjects, but use was not associated with disease severity. Although not associated with disease severity, $68 \%$ of BPD survivors had persistent radiological abnormalities compatible with chronic changes of BPD. Others have reported that radiological abnormalities improve with time (14), which was not observed in our dataset - a phenomenon possibly attributable to a selection bias because chest $\mathrm{x}$-rays were available for only a small proportion of subjects. In previous studies, lung function abnormalities were not related to the severity of neonatal respiratory illness $(14,17,25,26)$, which is in contrast to our finding of a clear association between greater severity of BPD, and greater abnormalities of $\mathrm{FEV}_{1}$, the $\mathrm{FEV}_{1} / \mathrm{FVC}$ ratio, forced expiratory flow over the midde one-half of the FVC (ie, $\mathrm{FEF}_{25-75}$ ) and functional residual capacity. This finding is supported by another study that reported a trend toward lower FEV (\% predicted) in moderate to severe BPD subjects among former preterm infants born between 1982 and 1985 (18). Our findings are in agreement with the previously described principle of 'dysanaptic' (ie, unequal) lung growth, which means normal growth of lung volume but not of airway size (14). When compared with Northway et al's earlier report of 'old' BPD subjects born between 1964 and 1973 (11), the overall airway obstruction and hyperinflation found in our study were more severe and likely represented an evolving phase of the pathophysiology of BPD between 'old' and 'new', while also representing the effects of greater prematurity and lower birth weight (11).

In one earlier study (24), infants with BPD had a higher risk of cerebral palsy and delays in cognitive and motor function compared with controls matched for gestational age at birth. A National Institute of Child Health and Human Development review on neurological developmental outcome of extreme low birth weight infants reported abnormal outcomes in $50 \%$ to $60 \%$ of infants with BPD. Findings in these reports are comparable with our BPD cohort, of whom $52 \%$ were found to have development delay and $20 \%$ had neurological impairment during childhood (24). Poor developmental outcomes were previously associated with prolonged hospital admissions and prolonged mechanical ventilation (24). In our study, we found an association between the presence of a developmental delay and the following variables: length of the initial hospital admission; duration of mechanical ventilation; and birth weight when correcting for BPD severity. Other associations were found between neurological impairment and the presence of neonatal seizures or a history of anoxic encephalopathy. In another study (27), the risks of impaired neurological development, cerebral palsy and/or low intellectual quotient were more than doubled in infants with severe BPD compared with infants with mild BPD; however, this trend in neurological impairment with BPD of increased severity was not found in our study. The prevalence of attention-deficit hyperactivity disorder in our BPD population was also significantly different from the general population $(6.5 \%$ versus $5.3 \%)(28,29)$ - an observation previously reported in preterm infants (30) but never linked to chronic lung disease or its 
TABLE 4

Long-term complications of prematurity according to bronchopulmonary dysplasia (BPD) severity

\begin{tabular}{|c|c|c|c|c|c|}
\hline & \multirow[b]{2}{*}{ All BPD } & \multicolumn{3}{|c|}{ BPD severity } & \multirow[b]{2}{*}{$P^{*}$} \\
\hline & & Mild & Moderate & Severe & \\
\hline Developmental delay $^{\dagger}$ & $87(52.3)$ & $12(34.3)$ & $45(58.4)$ & $30(78.9)$ & 0.003 \\
\hline Attention-deficit hyperactivity disorder ${ }^{\ddagger}$ & $12(6.5)$ & $3(8.6)$ & $5(5.8)$ & $3(6.5)$ & 0.37 \\
\hline Neurological impairment ${ }^{\dagger}$ & $33(20.4)$ & $5(14.3)$ & $18(23.4)$ & $8(21.0)$ & 0.41 \\
\hline Wheezing episodes/'asthma'§ & $35(34.2)$ & $14(35.9)$ & $33(35.9)$ & $16(34.0)$ & 0.43 \\
\hline Hearing impairment ${ }^{\dagger}$ & $18(11.4)$ & $2(5.7)$ & $11(14.315 .1)$ & $4(10.5)$ & 0.46 \\
\hline Low vision ${ }^{\dagger}$ & $29(17.9)$ & $4(9.1)$ & $16(20.8)$ & $8(21.1)$ & 0.29 \\
\hline Structural airway problems $^{\dagger}$ & $15(9.1)$ & $3(8.5)$ & $4(5.2)$ & $7(18.4)$ & 0.24 \\
\hline Cor pulmonale $\S$ & $8(4.4)$ & $0(0)$ & $4(4.7)$ & $3(6.5)$ & 0.08 \\
\hline
\end{tabular}

Data presented as $n$ (\%). The percentage value is based on the total number of subjects for whom each of the variables was assessed at predetermined ages. ${ }^{\star} P$ value for trend; ${ }^{\dagger}$ Cumulative incidence up to two years of age assessed in subjects followed up to two years; ${ }^{\ddagger}$ Cumulative incidence at any age assessed until the last follow-up in all subjects followed at the Montreal Children's Hospital (Montreal, Quebec) after initial discharge; ${ }^{\S}$ Cumulative incidence up to five years of age in subjects followed up to five years

TABLE 5

Crude and adjusted ORs of clinical factors with long-term complications of prematurity

\begin{tabular}{|c|c|c|c|c|c|c|}
\hline & \multirow{2}{*}{\multicolumn{2}{|c|}{$\begin{array}{c}\begin{array}{c}\text { Developmental delay } \\
\text { diagnosed by } 2 \text { years of age }\end{array} \\
\text { OR }(95 \% \mathrm{Cl}) \\
\end{array}$}} & \multirow{2}{*}{\multicolumn{2}{|c|}{$\begin{array}{c}\text { Attention-deficit hyperactivity } \\
\text { disorder* }\end{array}$}} & \multirow{2}{*}{\multicolumn{2}{|c|}{$\begin{array}{c}\begin{array}{c}\text { Neurological impairment } \\
\text { diagnosed by } 2 \text { years of age }\end{array} \\
\text { OR }(95 \% \mathrm{Cl})\end{array}$}} \\
\hline & & & & & & \\
\hline & Crude & Adjusted $^{\dagger}$ & Crude & Adjusted $^{\dagger \ddagger}$ & Crude & Adjusted $^{\dagger}$ \\
\hline Birth weight & $\begin{array}{c}1.01 / 100 \mathrm{~g} \\
(1.01-1.02)\end{array}$ & $\begin{array}{l}1.01 / 100 \mathrm{~g} \\
(1.01-1.02)\end{array}$ & $\mathrm{N} / \mathrm{S}$ & & $\mathrm{N} / \mathrm{S}$ & - \\
\hline Gestational age & $\begin{array}{c}\text { 1.09/week } \\
(0.97-1.19)\end{array}$ & - & $\begin{array}{c}1.45 / \text { week } \\
(1.15-1.79)\end{array}$ & $\begin{array}{c}1.25 / \text { week } \\
(1.06-1.82)\end{array}$ & $\begin{array}{c}1.11 / \text { week } \\
(0.98-1.26)\end{array}$ & - \\
\hline Days on mechanical ventilation & $\begin{array}{c}1.02 / \text { day } \\
(1.01-1.03)\end{array}$ & $\begin{array}{c}1.01 / \text { day } \\
(1.00-1.03)\end{array}$ & & & - & - \\
\hline Initial length of hospital stay & $\begin{array}{c}\text { 1.01/day } \\
(1.00-1.01)\end{array}$ & $\begin{array}{c}\text { 1.01/day } \\
(1.00-1.01)\end{array}$ & $\mathrm{N} / \mathrm{S}$ & - & $\mathrm{N} / \mathrm{S}$ & - \\
\hline Anoxic encephalopathy & N/S & - & N/S & - & $5.4(1.4-21.3)$ & $\mathrm{N} / \mathrm{S}$ \\
\hline Seizures & $\mathrm{N} / \mathrm{S}$ & - & N/S & - & $6.9(2.9-15.9)$ & $7.2(2.9-17.6)$ \\
\hline Postnatal corticosteroids & $\mathrm{N} / \mathrm{S}$ & - & $8.12(2.4-27.6)$ & $5.3(1.3-22.4)$ & $\mathrm{N} / \mathrm{S}$ & - \\
\hline Prenatal betamethasone & $\mathrm{N} / \mathrm{S}$ & - & $\mathrm{N} / \mathrm{S}$ & - & N/S & - \\
\hline Numbers of readmission & $1.2(1.1-1.3)$ & $1.1(1.1-1.2)$ & N/S & - & N/S & - \\
\hline Bronchopulmonary dysplasia severity & $1.9(1.2-3.0)$ & $\mathrm{N} / \mathrm{S}$ & N/S & - & $\mathrm{N} / \mathrm{S}$ & - \\
\hline
\end{tabular}

${ }^{*}$ As assessed at most recent follow-up; ${ }^{\dagger}$ OR adjusted for the variables listed in the first column, when found to be significant in a univariate analysis as well as for the degree of prematurity using gestational age (not in the case of developmental delay because collinearity was found between gestational age and birth weight); ${ }^{\ddagger}$ Also adjusted for low vision, hearing impairment and the duration of follow-up for each subject. N/S Not significant

treatment. In our study, attention-deficit hyperactivity disorder was associated with younger gestational age and the use of steroids postnatally, but not with the degree of BPD severity.

\section{Limitations}

The generalizability of our findings is enhanced because the cohort in the present study was comparable with previous cohorts. The mean gestational age in the present cohort was 27.9 weeks, similar to the mean gestational age of two other cohorts: 27.7 weeks (31) and 28.2 weeks (32). The incidence of pneumothorax, necrotizing enterocolitis, patent ductus arteriosus, retinopathy of prematurity, neonatal pneumonia or sepsis, and maternal factors, such as gestational diabetes, bleeding or prolonged rupture of membrane, were comparable with previously published studies $(23,31-35)$. In our cohort, $37 \%$ had severe BPD and $16.7 \%$ died, comparable with the $41 \%$ of severe BPD subjects in another study (31), and a reported $15.7 \%$ mortality in yet another study (33). The proportion of infants discharged home on oxygen was $26.1 \%$, which was similar to the previously published proportion of $25.9 \%$ in a very low birth weight BPD cohort (31). In an earlier study (14), $25 \%$ of adolescents with previous BPD reported current wheezing, compared with $34 \%$ of subjects in our study with wheezing episodes or asthma. Both estimates are much higher than the estimated prevalence of asthma in the general pediatric population $(11.5 \%)$ $(28,36,37)$.
The most important limitation of the present study was its observational design. The retrospective design resulted in missing data $-\mathrm{a}$ potentially important limitation. In 32 of the infants with BPD, the severity of illness could not be assessed using the NIH criteria, mainly because of transfer to other institutions. This represented 9.9\% of all those with BPD, and may have been patients with milder disease; thus, tending to overestimate the incidence of severe BPD. The number of subjects who were lost to follow-up over the years is another important limitation. After the initial discharge from hospital, $22 \%$ of the subjects were lost to follow-up, reflecting the role of the study centre as a tertiary referral centre. This might give rise to a selection bias toward more severe cases because nothing is known about the cases that were transferred to other institutions. Most of the data regarding long-term medication use and radiological findings involve subjects between five and 12 years of age because the proportion of subjects was fairly high up to 12 years of age, and the spectrum of BPD severity continued to include a similar proportion of subjects with mild, moderate and severe disease. Finally, only $29.5 \%$ of all infants received antenatal corticosteroids and only $9.3 \%$ of BPD cases were treated with exogenous surfactants. Hence, this group is commonly referred to as 'old' BPD cases. This limits the generalizability of the associations found, especially with regard to BPD severity because currently, all infants at risk for severe BPD will receive surfactant. 


\section{CONCLUSION}

The present study described an association between initial BPD severity and hospital readmission rate, long-term lung function and developmental delay. The severity of BPD was not associated with greater long-term use of inhalers or with persistent radiological abnormalities. In addition, the duration of mechanical ventilation and oxygen therapy was associated with developmental delay during childhood, and the use of postnatal corticosteroids was associated with the development of attention-deficit hyperactivity disorders. Initial BPD severity was an important predictor of pulmonary function abnormality and health care use during childhood. These findings contribute to a better description of the impact of BPD and its severity on long-term outcomes, and will help sensitize adult caregivers to the long-term consequences of preterm birth.

\section{REFERENCES}

1. Dimes Mo. White paper on preterm birth, the global and regional toll. White plains: March of Dimes Foundation, 2009.

2. Joseph KS, Kramer MS. Recent versus historical trends in preterm birth in Canada. CMAJ 1999;161:1409.

3. Statistics Canada, Public Health Agency. Measuring Up - A Health Surveillance Update on Canadian Children and Youth. 1999. <www.phac-aspc.gc.ca/publicat/meas-haut/mu_d-eng.php.> (Accessed on January 19, 2011).

4. Northway WH Jr, Rosan RC, Porter DY. Pulmonary disease following respirator therapy of hyaline-membrane disease. Bronchopulmonary dysplasia. N Engl J Med 1967;276:357-68.

5. Bancalari E, Claure N, Sosenko IR. Bronchopulmonary dysplasia: Changes in pathogenesis, epidemiology and definition. Semin Neonatol 2003;8:63-71.

6. Hulsmann AR, van den Anker JN. Evolution and natural history of chronic lung disease of prematurity. Monaldi Arch Chest Dis 1997;52:272-7.

7. Jobe AH, Bancalari E. Bronchopulmonary dysplasia. Am J Respir Crit Care Med 2001;163:1723-9.

8. Wohl ME. Bronchopulmonary dysplasia in adulthood. N Engl J Med 1990;323:1834-6.

9. Churg A, Golden J, Fligiel S, Hogg JC. Bronchopulmonary dysplasia in the adult. Am Rev Respir Dis 1983;127:117-20.

10. Samuels MP, Warner JO. Bronchopulmonary dysplasia: The outcome. Arch Dis Child 1987;62:1099-101.

11. Northway WH Jr, Moss RB, Carlisle KB, et al. Late pulmonary sequelae of bronchopulmonary dysplasia. N Engl J Med 199027;323:1793-9.

12. Northway WH Jr. Bronchopulmonary dysplasia: Twenty-five years later. Pediatrics 1992;89(5 Pt 1):969-73.

13. Parat S, Moriette G, Delaperche MF, Escourrou P, Denjean A, Gaultier C. Long-term pulmonary functional outcome of bronchopulmonary dysplasia and premature birth. Pediatr Pulmonol 1995;20:289-96.

14. Eber E, Zach MS. Long term sequelae of bronchopulmonary dysplasia (chronic lung disease of infancy). Thorax 2001;56:317-23.

15. Greenough A. Bronchopulmonary dysplasia - long term follow up. Paediatr Respir Rev 2006;(7 Suppl 1):S189-91.

16. Vrijlandt EJ, Gerritsen J, Boezen HM, Grevink RG, Duiverman EJ. Lung function and exercise capacity in young adults born prematurely. Am J Respir Crit Care Med 2006;173:890-6.

17. Doyle LW, Faber B, Callanan C, Freezer N, Ford GW, Davis NM. Bronchopulmonary dysplasia in very low birth weight subjects and lung function in late adolescence. Pediatrics 2006;118:108-13.
18. Halvorsen T, Skadberg BT, Eide GE, Roksund OD, Carlsen KH, Bakke P. Pulmonary outcome in adolescents of extreme preterm birth: A regional cohort study. Acta Paediatr 2004;93:1294-300.

19. Baraldi E, Filippone M. Chronic lung disease after premature birth. N Engl J Med 2007;357:1946-55.

20. Fanaroff AA, Stoll BJ, Wright LL, et al. Trends in neonatal morbidity and mortality for very low birthweight infants. Am J Obstet Gynecol 2007;196:147:e1-8.

21. Lavoie PM, Pham C, Jang KL. Heritability of bronchopulmonary dysplasia, defined according to the consensus statement of the National Institutes of Health. Pediatrics 2008;122:479-85.

22. Ehrenkranz RA, Walsh MC, Vohr BR, et al. Validation of the National Institutes of Health consensus definition of bronchopulmonary dysplasia. Pediatrics 2005;116:1353-60.

23. Landry JS, Menzies D. Occurrence and severity of bronchopulmonary dysplasia and respiratory distress syndrome after a preterm birth. Paediatr Child Health 2011;16:399-403.

24. Kinsella JP, Greenough A, Abman SH. Bronchopulmonary dysplasia. Lancet 2006;367:1421-31.

25. Chan KN, Noble-Jamieson CM, Elliman A, Bryan EM, Silverman M. Lung function in children of low birth weight. Arch Dis Child 1989;64:1284-93.

26. Kitchen WH, Olinsky A, Doyle LW, et al. Respiratory health and lung function in 8-year-old children of very low birth weight: A cohort study. Pediatrics 1992;89(6 Pt 2):1151-8.

27. Vohr BR, Coll CG, Lobato D, Yunis KA, O'Dea C, Oh W. Neurodevelopmental and medical status of low-birthweight survivors of bronchopulmonary dysplasia at 10 to 12 years of age. Dev Med Child Neurol 1991;33:690-7.

28. Greenbaum RL, Stevens SA, Nash K, Koren G, Rovet J. Social cognitive and emotion processing abilities of children with fetal alcohol spectrum disorders: A comparison with attention deficit hyperactivity disorder. Alcohol Clin Exp Res 2009;33:1656-70.

29. Merrill RM, Lyon JL, Baker RK, Gren LH. Attention deficit hyperactivity disorder and increased risk of injury. Adv Med Sci 2009;8:1-7.

30. Delobel-Ayoub M, Arnaud C, White-Koning M, et al. Behavioral problems and cognitive performance at 5 years of age after very preterm birth: The EPIPAGE Study. Pediatrics 2009;123:1485-92.

31. Bhutta ZA, Yusuf K. Neonatal respiratory distress syndrome in Karachi: Some epidemiological considerations. Paediatr Perinat Epidemiol 1997;11:37-43.

32. Smith VC, Zupancic JA, McCormick MC, et al. Trends in severe bronchopulmonary dysplasia rates between 1994 and 2002. J Pediatr 2005;146:469-73.

33. Payne NR, LaCorte M, Karna P, et al. Reduction of bronchopulmonary dysplasia after participation in the Breathsavers Group of the Vermont Oxford Network Neonatal Intensive Care Quality Improvement Collaborative. Pediatrics 2006;118(Suppl 2):S73-7.

34. Vohr BR, Tyson JE, Wright LL, Perritt RL, Li L, Poole WK. Maternal age, multiple birth, and extremely low birth weight infants. J Pediatr 2009;154:498-503.e2.

35. Valls i Soler A, Pijoan JI, Pallas Alonso CR, de la Cruz Bertolo J. [EuroNeoStat. A European information system on the outcomes of care for extremely low birth-weight infants]. An Pediatr (Barc) 2006;65:1-4.

36. Zoz DF, Parsons JP, Oman JL, et al. The prevalence of asthma in an NCAA Division I collegiate athletic program. J Asthma 2008;45:845-8.

37. Trepka MJ, Martin P, Mavunda K, Rodriguez D, Zhang G, Brown C. A pilot asthma incidence surveillance system and case definition: Lessons learned. Public Health Rep 2009;124:267-79. 


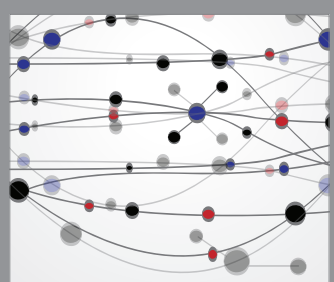

The Scientific World Journal
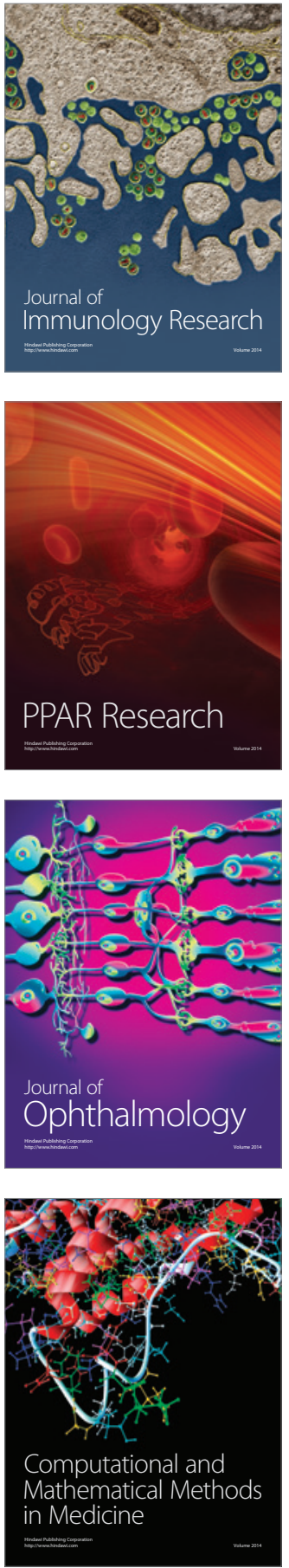

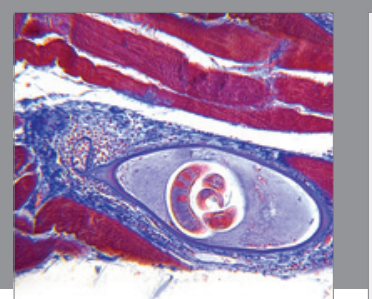

Gastroenterology Research and Practice

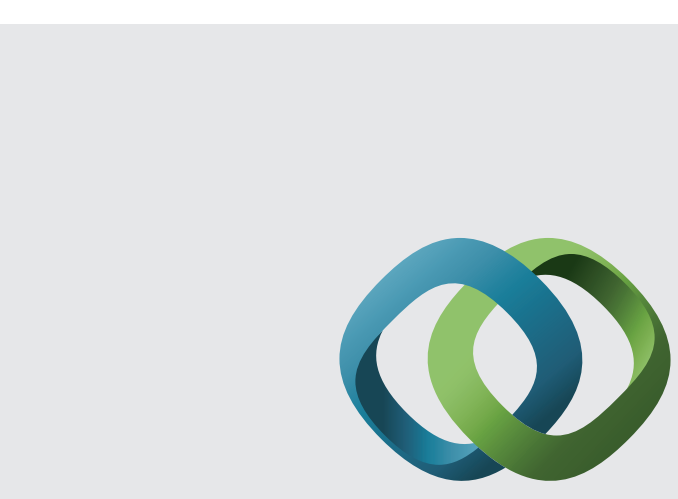

\section{Hindawi}

Submit your manuscripts at

http://www.hindawi.com
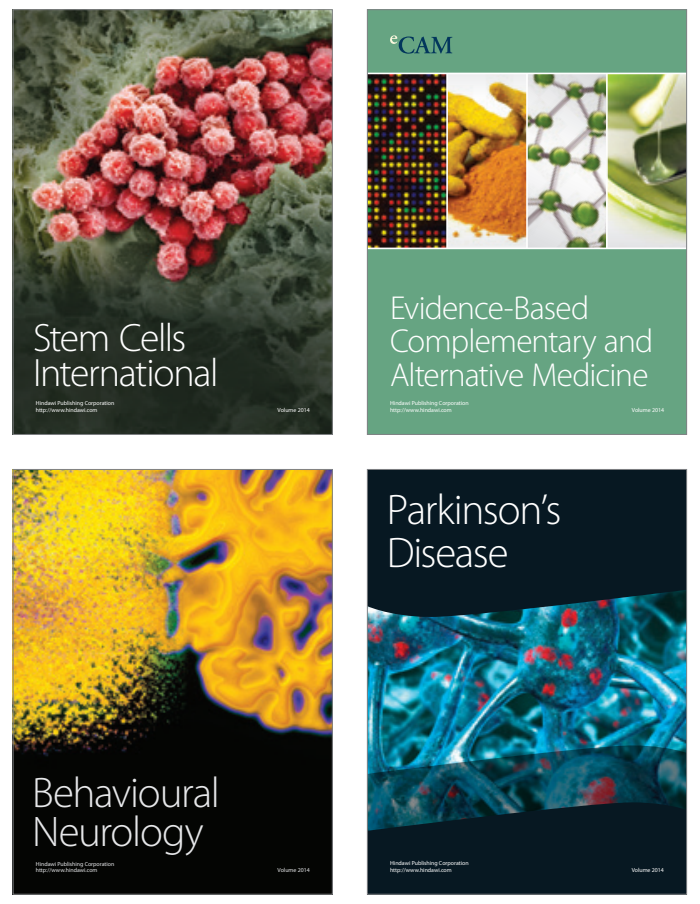
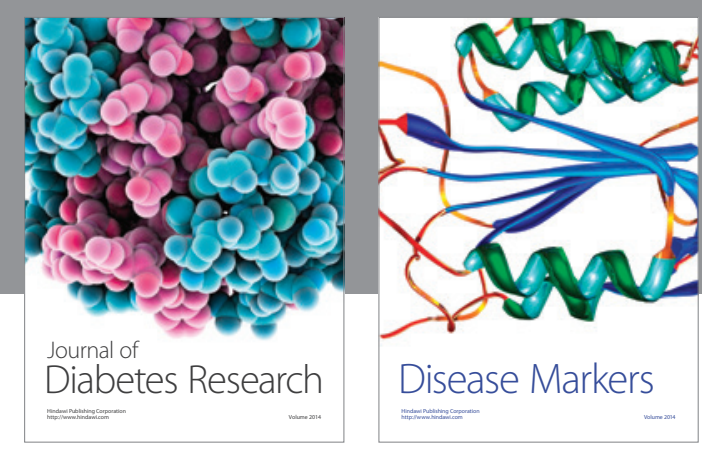

Disease Markers
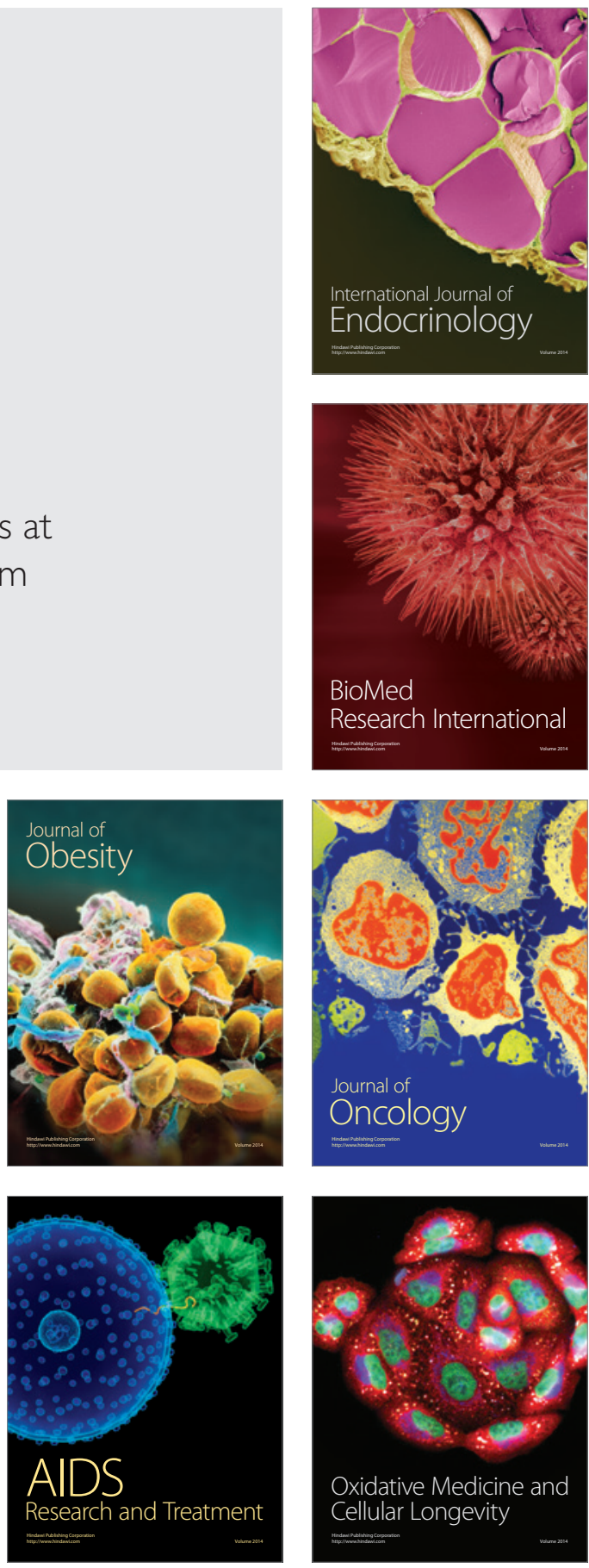